\title{
Photomechanical and Photochromic Behavior of a Molecule Containing Multiple Photoactive Groups ${ }^{\dagger}$
}

\author{
Manas K. Panda, ${ }^{\mathrm{a}}$ Nada ElAzhary, ${ }^{\mathrm{a}}$ Mouza A. Alzaabi, ${ }^{\mathrm{b}}$ Brandon M. Wahba, ${ }^{\mathrm{a}}$ \\ Jolly Jacob, ${ }^{b}$ and Panče Naumova, \\ ${ }^{a}$ New York University Abu Dhabi, PO Box 129188, Abu Dhabi, United Arab Emirates \\ b Abu Dhabi University, PO Box 59911, Abu Dhabi, United Arab Emirates \\ RECEIVED JUNE 2, 2014; REVISED OCTOBER 29, 2014; ACCEPTED NOVEMBER 6, 2014
}

\begin{abstract}
Photomechanical and photochromic activities are reported for single crystals of a new multiresponsive material, 2,4-di-tert-butyl-6-((E)-((4-((E)-phenyldiazenyl)phenyl)imino)methyl)phenol (Azim1), with two photoactive groups that can undergo photoisomerization (azo and imine), and an orthohydroxy group that is capable of proton transfer. Upon irradiation with UV light, platy and needle-shaped crystals of Azim-1 rapidly bend towards the light source and return to their initial shape as soon as the irradiation is terminated. Upon prolonged exposure to UV light, the crystals change their color from yellow to red. The crystal structure of non-irradiated Azim-1 is reported, and the mechanisms of the photomechanical and photochromic responses are discussed.
\end{abstract}

Keywords: photochromism, photomechanical effects, proton transfer, Schiff base, tautomerism

\section{INTRODUCTION}

The amplification of stimuli-induced molecular motions to macroscopic mechanical motions has attracted huge interest from both basic and applied research standpoint. ${ }^{1-12}$ Light-induced mechanical processes are clean and convenient because they can be remotely controlled without any wire connections, as well as because of abundance of natural light source, without generation of harmful side products. ${ }^{13-19}$ In contrast with orderdisordered phase transitions in elastomeric actuators, the driving force behind the motility of single crystals stems from geometric isomerism (e.g. trans-cis or keto-enol) or photochemical reactions, such as ring opening / closure. ${ }^{20-22}$ Materials containing the azobenzene moiety typically undergo mechanical reconfiguration, such as bending under UV light. This reversible motion is rooted in the trans-cis photoisomerization in the molecule that results in macroscopic movement of the object. ${ }^{23-26}$ Similarly, the salicylideneanilines, a class of $o$-hydroxy Schiff bases with strong intramolecular H-bonding between the hydrogen atom of the hydroxyl group $(-\mathrm{OH})$ group and nitrogen atom of the imine group $(-\mathrm{C}=\mathrm{N}-)$ exhibit reversible photochromism due to excited-state proton transfer between two tautomers, viz., enol-imine $(\mathrm{OH})$ and keto-enamine $(\mathrm{NH})$ forms, followed by geometrical isomerism. ${ }^{27-28}$ Here, we have combined the favorable properties of the azobenzenes and salicylideneanilines in a single entity in order to achieve concomitant display of mechanical motion and photochromism. Such polystable materials could be of interest as active material for optoelectronic actuating devices. Specifically, with the aim of developing mechanically active photochromic molecule, we have designed and synthesized the molecule Azim-1 (Scheme 1), a prototypical photochemical switch with two photoactive functional groups, an azo $(-\mathrm{N}=\mathrm{N}-)$ and imine $(-\mathrm{C}=\mathrm{N}-)$. The molecule was synthesized by the Schiff base reaction between 3,5-di-tert-butyl-2hydroxybenzaldehyde and 4-aminoazobenzene in refluxing ethanol. The compound was characterized by
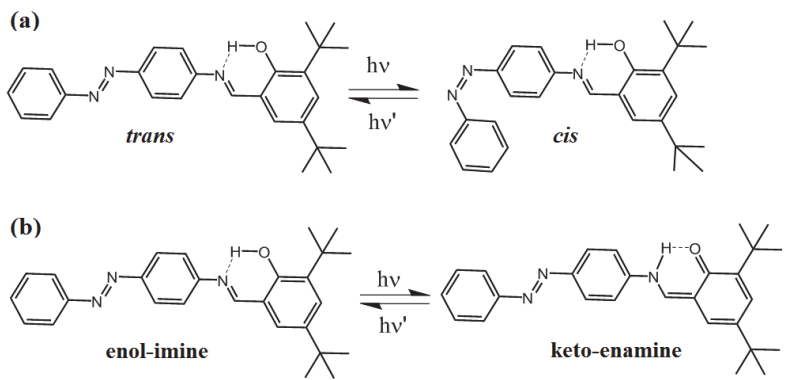

Scheme 1. Trans-cis isomerism and imine-enamine tautomerism in Azim-1.

\footnotetext{
$\dagger$ Dedicated to Dr. Mirjana Eckert-Maksić on the occasion of her $70^{\text {th }}$ birthday.

* Author to whom correspondence should be addressed. (E-mail: pance.naumov@nyu.edu)
} 
${ }^{1} \mathrm{H}$ NMR, IR, UV-Vis spectroscopies and single crystal $\mathrm{X}$-ray diffraction.

\section{EXPERIMENT AND METHODS}

3,5-di-tert-butyl-2-hydroxybenzaldehyde was purchased from TCI and 4-aminoazobenzene was purchased from $\mathrm{BDH}$, and used as received. Azim-1 was prepared by Schiff base condensation of 3,5-di-tert-butyl-2hydroxybenzaldehyde and 4-aminoazobenzene in refluxing ethanol for 3 hours. Plate-like crystals and large single crystals were grown by slow evaporation of methanol solution. For the kinematic studies, the crystals were mounted on the tip of a thin glass rod with adhesive and subjected to bend. The Ushio SP-7 spot cure system with maximum wavelength at $365 \mathrm{~nm}$ was used as UV-light source. The UV-visible spectra were recorded at room temperature in absorption mode with Shimadzu UV-3600 UV-Vis-NIR spectrometer. The IR spectra were recorded with Agilent Cary 600 series FTIR spectrometer using KBr pellets. The Differential Scanning Calorimetry (DSC) analysis was carried out on TA DSC-Q2000 instrument, using $c a$. 2-3 mg of the samples placed on a Tzero aluminium pan and heated from room temperature to the selected temperature with a heating rate of $10{ }^{\circ} \mathrm{C} \mathrm{min}-1$. Scanning electron microscopy (SEM) was carried out with a QUANTA FEG 450 electron microscope with primary electron energy of 1$2 \mathrm{kV}$ at room temperature. The crystals were attached to silicon wafers with oil or adhesive. Single crystal X-ray data collections were performed on a Bruker APEX DUO diffractometer with monochromated $\operatorname{Mo} K_{\alpha}$ radiation $(\lambda=0.71069 \AA)$ with $\mathrm{CCD}$ as area detector. $^{29}$ All crystallographic calculations were performed using crystallographic software (APEX 2, version 2014.1-1, Bruker AXS). The structures were determined by the intrinsic method. The non-hydrogen atoms were refined anisotropically, and the hydrogen atoms were located in the calculated positions. ${ }^{30-32}$

\section{RESULTS AND DISCUSSION}

The molecule was synthesized by the Schiff base reaction between 3,5-di-tert-butyl-2-hydroxybenzaldehyde and 4-aminoazobenzene in refluxing ethanol. The compound was characterized by ${ }^{1} \mathrm{H} \mathrm{NMR}$, IR and UV-Vis spectroscopy, and X-ray crystallography. ${ }^{1} \mathrm{H}$ NMR spectra (DMSO- $d_{6}$ ) showed characteristic peaks at $9.04 \mathrm{ppm}$ and $13.79 \mathrm{ppm}$ that correspond to the $\mathrm{C} \underline{\mathrm{H}}=\mathrm{N}$ and $\mathrm{OH}$ groups, respectively.

The IR spectra showed characteristic band for $-\mathrm{C}=\mathrm{N}$ stretching at $1571 \mathrm{~cm}^{-1}$ and $\mathrm{N}=\mathrm{N}$ stretching at $1616 \mathrm{~cm}^{-1}$. The phenolic $\mathrm{O}-\mathrm{H}$ peak was observed at $3378 \mathrm{~cm}^{-1}$ (Figure 4). UV-Vis spectra of Azim-1 in ethanol exhibited a broad band around $350 \mathrm{~nm}$ that corresponds to overlapped absorptions of the $\mathrm{C}=\mathrm{N}$ and $\mathrm{N}=\mathrm{N}$ groups.

Plate-like thin crystals and bulk single crystals of Azim-1 were grown from methanol solution. In crystalline state, Azim-1 exists in trans azo form (Figure 5a). On comparisons with face indices of bulk single crystals, we identified the surface of the thin plates as the (001) face along the longest side ( $b$-axis) of the crystal. Figure 1a depicts frontal view of the (001) face of thin plate-like crystals. The average thickness of the plate crystals was $10 \mu \mathrm{m}$ from the SEM micrographs (Figure 1c, d).

In order to test the photomechanical behavior of Azim-1, thin plate-like crystal of size $600 \mu \mathrm{m} \times$ $118.4 \mu \mathrm{m} \times 10 \mu \mathrm{m}$ was attached to the end of a glass needle with adhesive and subjected to UV radiation from one side. Upon photoirradiation $(365 \mathrm{~nm})$ on the (001) surface, the crystal rapidly bent towards the light source, and remained bent as long as it was exposed. The crystal recovered its initial shape as soon as the radiation was terminated (Figure 2a-f, Movie S1). A maximum bending of $3.5^{\circ}$ was achieved in the first cycle. The reversibility of the bending motion was observed by alternative irradiation for $4 \mathrm{~s}$ separated by $5 \mathrm{~s}$ of dark periods. The deflection gradually decreased in subsequent cycles, reaching only $1.5^{\circ}$ at the $4^{\text {th }}$ cycle (Figure 2g).

In addition to bending motion, we also observed that the crystal changed its color from yellow to orangered upon exposure to UV light of intensity $300 \mathrm{~W} \mathrm{~m}^{-2}$. The color change was observed both for crystal as well as for powder sample of Azim-1 (Figure 3). This color change is due to photoinduced conversion of the enolimine form to the keto-enamine form via intramolecular proton transfer (Scheme 1b). Longer exposure to UV
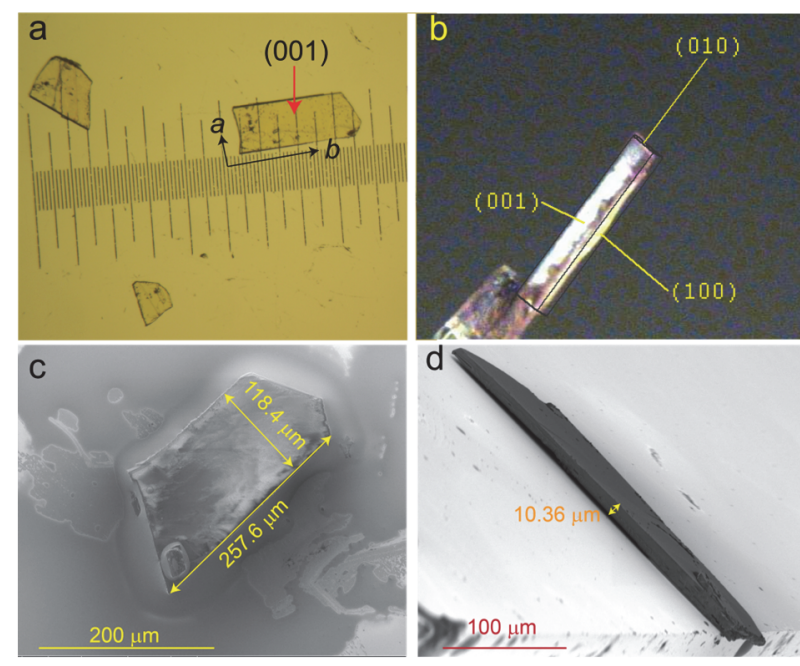

Figure 1. Crystal habit and face indices of crystalline Azim-1. 


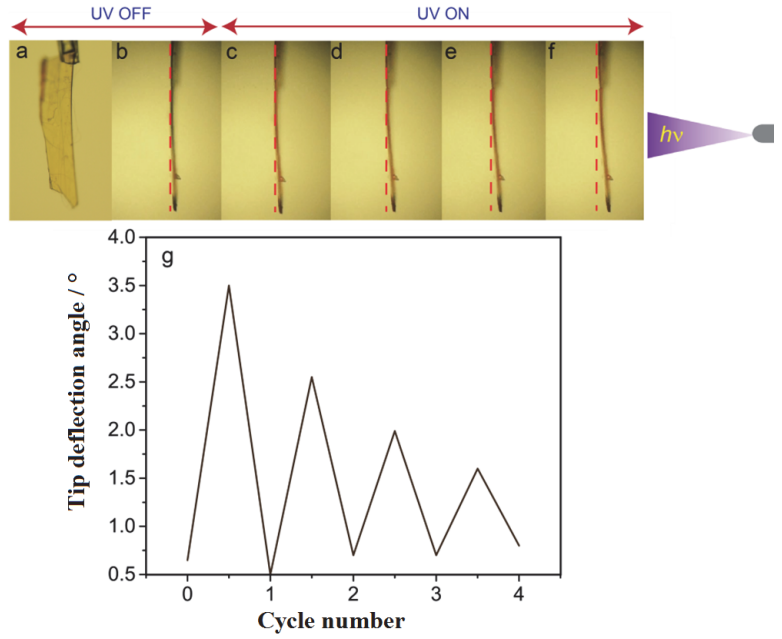

Figure 2. Photobending of a thin plate crystal of Azim-1 shown $(\mathrm{a}, \mathrm{b})$ before, and $(\mathrm{c}-\mathrm{f})$ during exposure to ultraviolet (UV) light; (g) reversible bending and gradual decrease of the tip deflection after 4 cycles.

light leads to apparent surface melting of the crystals, resulting in enhanced roughness of the crystal surface. Although our DSC analysis showed that the pure yellow crystals melt at $\sim 140{ }^{\circ} \mathrm{C}$, the lowering of melting point under UV light is due to the presence of reactant and photoisomer product. IR spectra exhibited change in $v_{\mathrm{C}=\mathrm{N}}$ stretching frequency due to conversion of the enolimine form to keto-enamine (Figure 4). The intensity of $\mathrm{O}-\mathrm{H}$ stretching mode also decreased with gradual photoirradiation, in support of the enol-keto isomerization.

In order to clarify the bending motion with the aid of the crystal structure of Azim-1, we carried out single crystal X-ray crystallography. The yellow crystal of Azim-1 crystallizes in the monoclinic system, space group $P 2_{1}$. Figure $5 \mathrm{a}$ depicts the crystal structure of
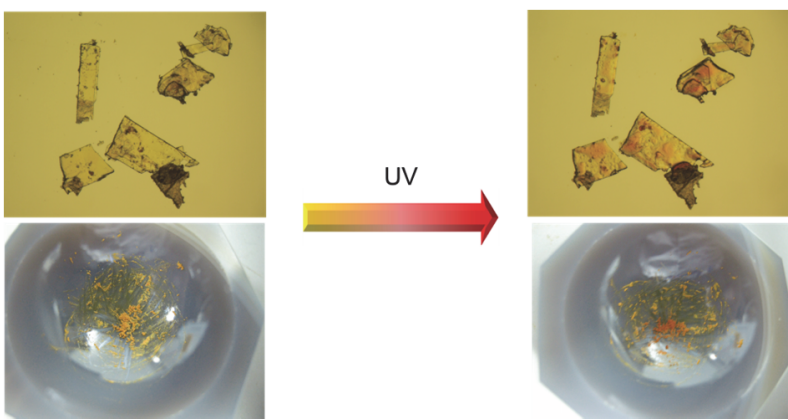

Figure 3. Color change of yellow plate crystals of Azim-1 upon ultraviolet (UV) irradiation $\left(365 \mathrm{~nm}, 300 \mathrm{~W} \mathrm{~m}^{-2}\right)$.

Azim-1. The molecule possesses planar structure with stacked layers. The molecules are oriented in head-tohead fashion on single layer parallel to the $(010)$ plane while stacked in head-to-tail fashion atop each other perpendicular to the (010) plane. The azo groups and enol-imine groups are roughly oriented along the diagonal of the same plane. The average perpendicular distance between two molecules lying in two layers is $3.575 \AA$. Intramolecular hydrogen bond between $\mathrm{N}$ of the $\mathrm{C}=\mathrm{N}$ group and the $\mathrm{H}$ atom of the phenolic $-\mathrm{OH}$ group of the salicylaldehyde ring was observed in the structure at $298 \mathrm{~K}$. The $\mathrm{H} \cdots \mathrm{O}$ distance and $\mathrm{N} \cdots \mathrm{O}$ distances are $1.88 \AA$ and $2.618 \AA$ respectively, while the $\mathrm{N} \cdots \mathrm{H}-\mathrm{O}$ angle is $132.5^{\circ}$.

We observed that photoirradiation causes bending of the plate crystal towards the light source, indicating contraction of illuminated surface due to formation of photoproducts. As can be seen from packing features in Figure 5, the molecules are stacked on top of each other along the $b$-axis (longitudinal axis of the plate crystal, Figure 1). The azo groups are oriented along the diagonal of the (010) plane, i.e., approximately along the $c$-axis of the unit cell. The tert-butyl groups are

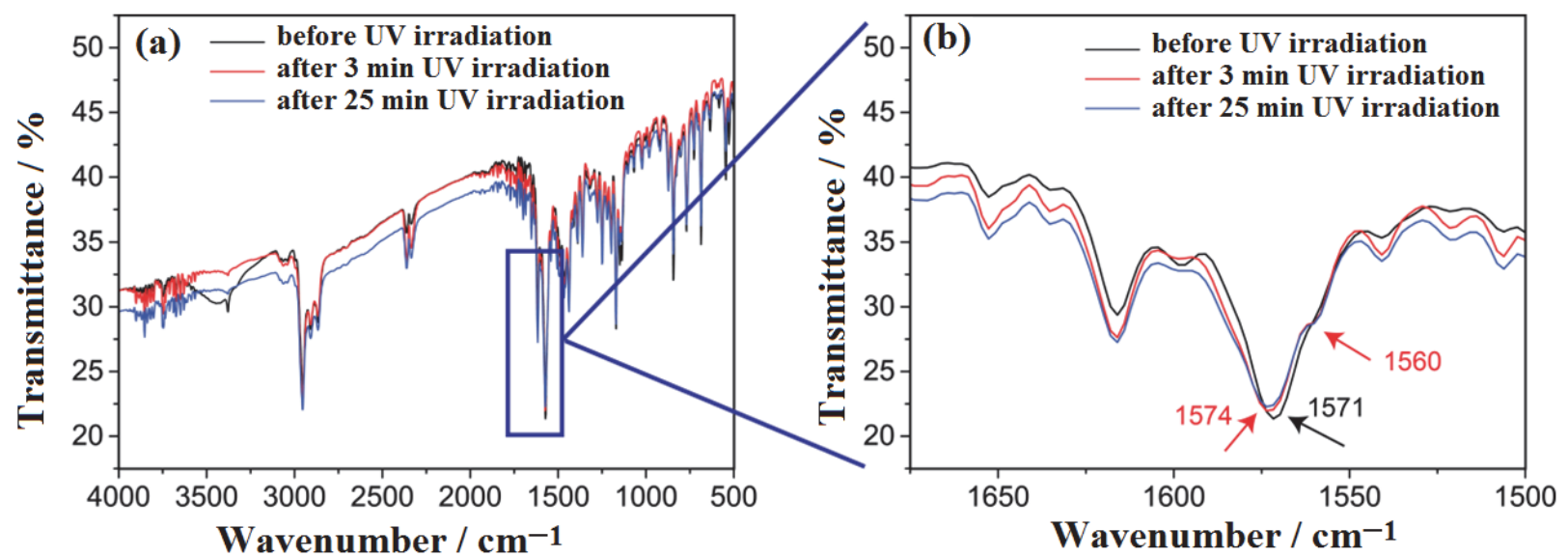

Figure 4. IR spectra (KBr pellet) of Azim-1. (a) Full spectrum; (b) the $1675-1500 \mathrm{~cm}^{-1}$ spectral region. 
oriented in a face-to-face manner along $b$-axis. On UV illumination, trans to cis isomerization of azo group in the molecules on irradiated (001) surface induces shrinking of the crystal along $c$-axis, while the cell axes on non-illuminated side $(00 \overline{1})$ remains intact. This nonuniform distribution of reactant and photoproduct phase resulted in developing interfacial stress that causes bending of the crystal. The bending however reaches a limit due to the steric hindrance between the molecules by tert-butyl groups along $b$-axis (Figure $5 \mathrm{c}$, d). The small deflection angle of Azim-1 crystals when irradiated on the (001) surface can be explained in terms of the orientation of the azo groups along $c$-axis. If azo groups were oriented along the longitudinal axis (in this case $b$ axis), we could expect larger deflection while irradiating on (001) surface.

\section{CONCLUSION}

The plate crystals of Azim-1 exhibit reversible photomechanical bending upon irradiation with UV light. The bending motion was caused by the developed interfacial strain due to asymmetric distribution of the photoisomerization product and the reactant on the illuminated and non-illuminated face of the crystal, respectively. The shape change of the crystal is possibly a result of the cell axis deformation upon UV irradiation.

Associated Contents. Movies for photobending, Figures and CIF file of Azim-1 are provided in supporting information.

Funding Sources. This work is financially supported by funding from New York University Abu Dhabi.
Table 1. Basic crystallographic data for Azim-1 at 298 K

\begin{tabular}{|c|c|}
\hline$T / \mathrm{K}$ & $298 \mathrm{~K}$ \\
\hline Chemical formula & $\mathrm{C}_{2}{ }_{2} \mathrm{H}_{31} \mathrm{~N}_{3} \mathrm{O}$ \\
\hline$M_{\mathrm{r}}$ & 413.55 \\
\hline Crystal system & Monoclinic \\
\hline Space group & $P 2_{1}$ \\
\hline$a / \AA$ & $9.409(8)$ \\
\hline$b / \AA$ & $7.123(6)$ \\
\hline$c / \AA$ & $16.804(14)$ \\
\hline$\alpha=\gamma$ & 90.00 \\
\hline$\beta$ & $97.38(2)$ \\
\hline$V / \AA^{3}$ & $1116.9(16)$ \\
\hline$Z$ & 2 \\
\hline$\rho_{\text {calc }} / \mathrm{g} \mathrm{cm}^{-3}$ & 1.230 \\
\hline$\mu / \mathrm{mm}^{-1}$ & 0.075 \\
\hline$F_{000}$ & 444 \\
\hline$\theta_{\min } /{ }^{\circ}$ & 2.10 \\
\hline$\theta_{\max } /^{\circ}$ & 25.471 \\
\hline Reflections collected & 19890 \\
\hline Independent reflections & 3724 \\
\hline$G o F$ & 1.314 \\
\hline $\begin{array}{l}\text { Final } R \text { indices } \\
\quad[I>2 \sigma(I)]\end{array}$ & $R_{1}=0.1436, w R_{2}=0.3461$ \\
\hline Flack X parameter & $2.3(10)$ \\
\hline
\end{tabular}

Acknowledgements. We thank Dr. James Weston for his help with the SEM study and Dr. Holger Ott (Bruker AXS GmbH, Karlsruhe, Germany) for the advice with the refinement of the crystal structure of Azim-1. We also thank Mrs Jane Toye for editing the manuscript. (a)

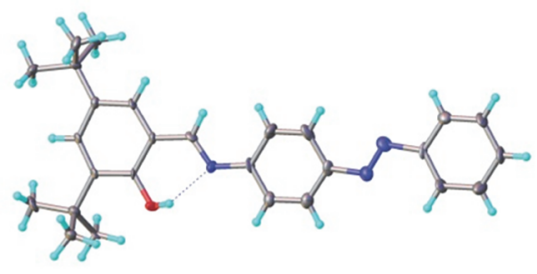

(c)

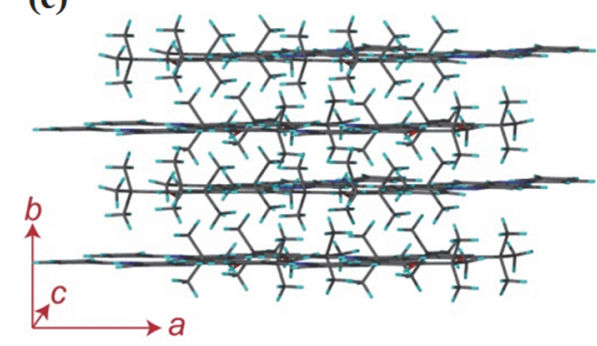

(b)

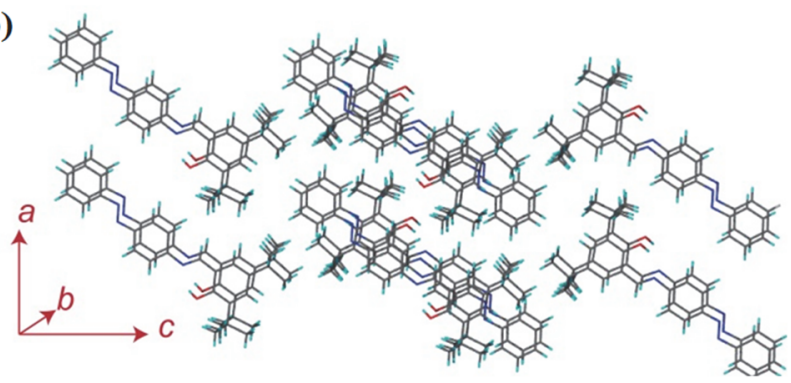

(d)

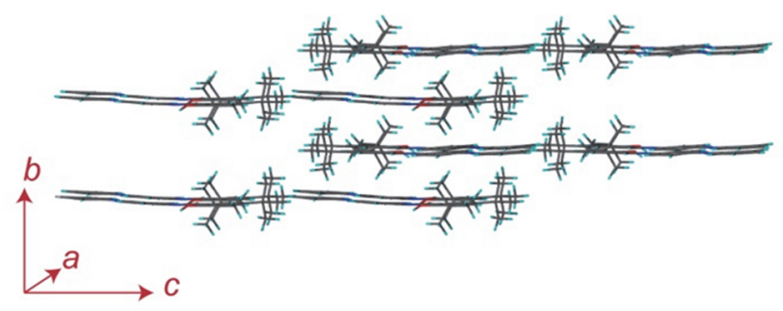

Figure 5. Crystal packing of Azim-1. 


\section{REFERENCES}

1. S. Kobatake, S. Takami, H. Muto, T. Ishikawa, and M. Irie, Nature 446 (2007) 778-781.

2. M. K. Panda, T. Runčevski, S. C. Sahoo, A. A. Belik, N. K. Nath, R. E. Dinnebier, and P. Naumov, Nature Commun. 5 (2014), article number: 4811.

3. S. C. Sahoo, M. K. Panda, N. K. Nath, and P. Naumov, J. Am. Chem. Soc. 135 (2013) 12241-12251.

4. F. D. Jochum and P. Theato, Chem. Soc. Rev. 42 (2013) 74687483.

5. M. A. C. Stuart, W. T. S. Huck, J. G. M. Müller, C. Ober, M. Stamm, G. B. Sukhorukov, I. Szleifer, V. V. Tsukruk, M. Urban, F. Winnik, S. Zauscher, I. Luzinov, and S. Minko, Nature Mater. 9 (2010) 101-113.

6. X. Yan, F. Wang, B. Zheng, and F. Huang, Chem. Soc. Rev. 41 (2012) 6042-6065.

7. I. Tokarev and S. Minko, Soft. Matter. 5 (2009) 511-524.

8. I. Tokarev and S. Minko, Adv. Mater. 21 (2009) 241-247.

9. G. R. Hendrikson and L. A. Lyon, Soft Matter. 5 (2009) 29-35.

10. S. Lee, S. Oh, J. Lee, Y. Malpani, Y-S. Jung, B. Kang, J. Y. Lee, K. Ozasa, T. Isoshima, S. Y. Lee, M. Hara, D. Hashizume, and J-M. Kim, Langmuir 29 (2013) 5869-5877.

11. L. D. Zarzar and J. Aizenberg, Acc. Chem. Res. 47 (2014) 530539.

12. P. Fratzl and F. G. Barth, Nature 462 (2009) 442-448.

13. G. A. Abakumov and V. I. Nevodchikov, Dokl. Akad. Nauk SSSR 266 (1982) 1407-1410.

14. F. Terao, M. Morimoto, and M. Irie, Angew. Chem. Int. Ed. 51 (2012) 901-904.

15. B. I. Yakobson, E. V. Boldyreva, and A. A. Sidelnikov, Proc. Sib. Dept. Acad. Sci. USSR 51 (1989) 6-10.

16. T. Kim, M. K. Al-Muhanna, S. D. Al-Suwaidan, R. O. Al-Kaysi, and C. J. Bardeen, Angew. Chem. Int. Ed. 52 (2013) 6889-6893.
17. L. Zhu, R. O. Al-Kaysi, C. J. Bardeen, J. Am. Chem. Soc. 133 (2011) 12569-12575.

18. P. Naumov, S. Sahoo, B. Zakharov, and E. Boldyreva, Angew. Chem. Int. Ed. 52 (2013) 9990-9995.

19. N. K. Nath, L. Pejov, S. M. Nichols, C. Hu, N. Saleh, B. Kahr, and P. Naumov, J. Am. Chem. Soc. 136 (2014) 2757-2766.

20. T. Kim, L. Zhu, L. J. Mueller, and C. J. Bardeen, CrystEngComm. 14 (2012) 7792-7799.

21. L. Zhu, R. O. Al-Kaysi, R. J. Dillon, F. S. Tham, and C. J. Bardeen, Cryst. Growth Des. 11 (2011) 4975-4983.

22. M. Morimoto and M. Irie, J. Am. Chem. Soc. 132 (2010) 14172 14178.

23. H. Koshima and N. Ojima, Dyes Pigm. 92 (2012) 798-801.

24. O. S. Bushuyev, A.Tomberg, T. Friscic, and C. J. Barrett, J. Am. Chem. Soc. 135 (2013) 12556-12559.

25. O. S. Bushuyev, T. A. Singleton, and C. J. Barrett, Adv. Mater. 25 (2013) 1796-1800.

26. H. Koshima, N. Ojima, and H. Uchimoto, J. Am. Chem. Soc. 131 (2009) 6890-6891.

27. H. Koshima, K. Takechi, H. Uchimoto, M. Shiro, and D. Hashizume, Chem. Commun. 47, (2011), 11423-11425.

28. H. Koshima, R. Matsuo, M. Matsudomi, Y. Uemura, and M. Shiro, Cryst. Growth Des. 13 (2013) 4330-4337.

29. APEX2, versionv2014.90, and SAINT, version 7.34A; Bruker AXS Inc., Madison, WI, 2014.9.0.

30. Sheldrick, G. M. SADABS, University of Göttingen, Göttingen, Germany, 1996.

31. Sheldrick, G. M. A. Short History of SHELX, Acta Crystallogr. A 64 (2008) 112-122.

32. Sheldrick, G. M., SHELXS-2013, 2014, University of Göttingen: Göttingen, Germany.

33. Sheldrick, G. M., SHELXL-2013, 2014, University of Göttingen: Göttingen, Germany. 